\title{
Decimating an Oligopoly: Study of how Jio Telecoms conquered the Indian Network Industry
}

\author{
Joydeb Debnath \\ University Institute of Science, Department of mathematics \\ Chandigarh university, Ghuran, Punjab 140413
}

\begin{abstract}
One of the most debatable and informational business contemplates is that of how Reliance Jio took over a commercial center control by BSNL, the latter who is uncertain of staying alive these days. Among a concise range, viable ways were utilized by Jio and the awkward obstacles looked at by BSNL lead to the creation of one the biggest network providers in India and furthermore made an exceptionally beneficial organization go to obligation. The paper expects to reveal the components and factors for BSNLs ruin and the manner in which it influenced the insights of telephone clients inside the nation. This paper furthermore reveals insight into Jio selling its SIM card without charge and the undeniable reality that not charging any money for a long time since its release changed the total telephone-charge structure in the nation. It's a comprehensive report on the monetary, political, and psychological ways utilized by a shiny new organization known as Jio and its uncommon impacts until now, where Jio holds over half piece of the pie. The discoveries of this examination are masterminded get into terms of the effect on the all-out scope of endorsers in accordance with the Telecom Statistics India Reports from 2019.T
\end{abstract}

Keywords-India's Telecom Networks, BSNL, Reliance JIO, Telecommunications

\section{INTRODUCTION}

\subsection{Telecom Business of India}

BSNL's letters set up a title and a momentous story. There's no higher model than that of Jio: a starter who comes in and annihilates an entire oligopoly. Reliance Jio has triumphed over telecom goliaths like BSNL, Airtel, and Vodaphone. It had more than one Crore subscribers within one month of its unharness. The greater part of them, were previous subscribers of BSNL, Bharti Airtel, Vodaphone, and Idea, benefactors of many years old network providers. It turns into a level of discussion to see how one starter had a particularly revolutionary result on an oligopolistic market. Along these lines, how was it done by Mukesh Ambani and Jio? How about we see the full story.[1]

\subsection{BSNL Before the Launch of JIO}

The govt. of India introduced BSNL in the year 2000 and it's headquartered in the capital of India as of these days. Bharat Sanchar Nigam confined (BSNL), one among the four public sector organizations inside the nation might be a unit name to a few Indians. Its achievement in its magnificence days topped. Notwithstanding, it as of late stopped. In 2014, it's remote and wired administrations had a consolidated piece of the overall industry of $28.22 \%$ followed via Airtel who had a piece of the pie of 20.68 percent. Additionally, BSNL was one among the couple of media transmission firms that was running on a benefit of around 10,000 crores, ensuing monetary and operational profit. BSNL started to lose its quality from 2014 to 2016, as its adversaries ventured up and started giving $4 \mathrm{G}$ organization speeds. The $4 \mathrm{G}$ range wasn't reachable to BSNL by then. And in mid-2016, Reliance Jio entered the exchange and BSNL started losing endless its dynamic client base quickly.

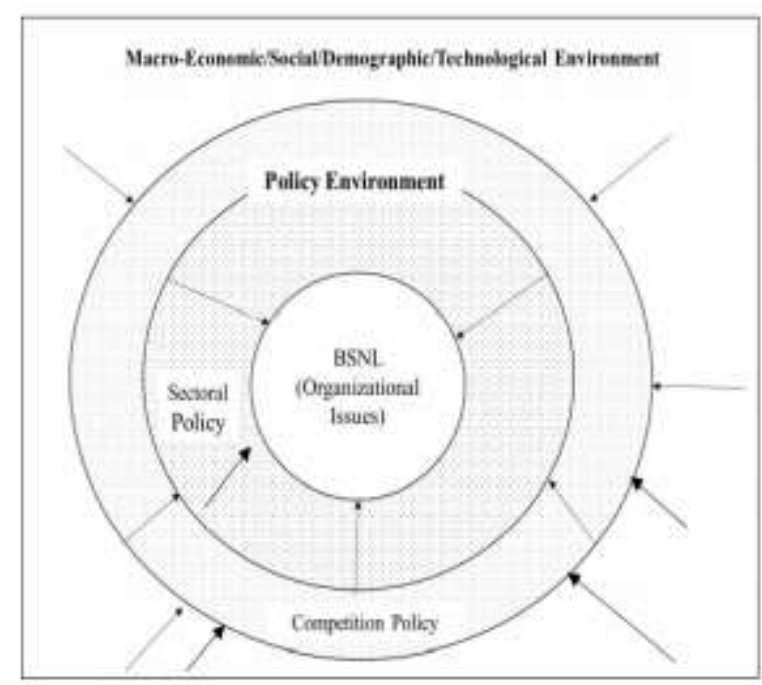

Figure 1: Report on Revival /Restructuring of BSNL IIM A [2]

\subsection{JIO's Arrival}

Jio Soft was released in 2015, and on September 5, 2016, it was made publicly offered and openly advertised. All clients with a service pack were offered $4 \mathrm{G}$ rates and limitless free voice calls. Also, they made obtaining the SIM cards without cost. All through the nation, people arranged in Brobdingnagian numbers to state this offer. Inside the expectation of countering the enormous misfortunes they were enduring, distinctive 4G companies like Airtel brought down their levy plans. In any case, Jio made it clear that its customers were free to utilize the SIM card in December 2016, all significant telecom providers got an immense blow, bringing JIO's quality up in products. solely to market the new network, it absolutely was allowed to wave off an expected tax revenue of about 5,000 Crores.

In the meanwhile, the BSNL specialists and representatives' associations were restless concerning their work in a very business that was at that point sinking down. Laborers' groups recorded letters and a few different bids were made to change into the $4 \mathrm{G}$ range and encourage a battle. All requests to 
upgrade to $4 \mathrm{G}$, were turned down. This constrained BSNL to a failing battle and watch their piece of the overall industry go down with no idea to why they probably can't supply steady supplies such as Jio.

\begin{tabular}{|c|c|c|}
\hline $\begin{array}{l}\text { Helisnce Jie Band A } \\
\text { Taponegy }\end{array}$ & Peliance An bela frequency & $\begin{array}{l}\text { Relarvee 2le } \\
\text { Bindwits }\end{array}$ \\
\hline 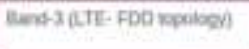 & 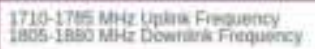 & 5 the \\
\hline Bavs5 RTE- FDO Nopologen] & 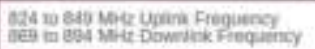 & 5 Motz \\
\hline Eano 40 (L.TE TDD kapology? & 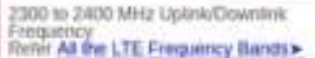 & $20 \mathrm{MHE}$ \\
\hline
\end{tabular}

Table 1: Frequency Range of JIO, using BAND 3, 5 and 40 for it's $4 G$ network

\subsection{Government Guidelines Played a Vital Role}

With the immense misfortunes it had been confronting, BSNL couldn't get by. The all-around injured organization trusted they may be rescued by the govt. With a few faithful clients who were as yet joined to $3 \mathrm{G}$ telephones, it actually had its acknowledgment and status. Nonetheless, when Jio announced that its services were free for an extra three months, they got another blow. This made individuals who were unconscious of those brilliant arrangements prior to enrolling in Jio, terrified of missing out on them.

Numerous BSNL workers and heads of the Union fault the government led by NDA for making comfort for Reliance Jio to beat such piece of the pie. Indeed, along with his clear promotions on the network and his dreams of a Digital India, Prime Minister Narendra Modi himself resembled Jio's entire representative. On the contrary hand, without precedent for a very long time, BSNL, for the first time, couldn't pay wages to its provisional worker. Throughout now, several of the demonstrations and revolts were brought on, several of that criticized the govt. for being pro-corporate.

Inter-Network fees mean the number charged to the service supplier of the receivers by the callerr's service supplier for connecting a call. fourteen paise per call were the conventional fees charged then. For all the networks, this was traditional. On the opposite hand, once Jio submitted a proposal to attenuate the web work fees it had to pay, the govt. reduced it from fourteen paise to six pasie. Until now, such a discount was unheading. Earlier demands by Airtel.

\section{AFTER RELIANCE JIO'S ESTABLISHMENT}

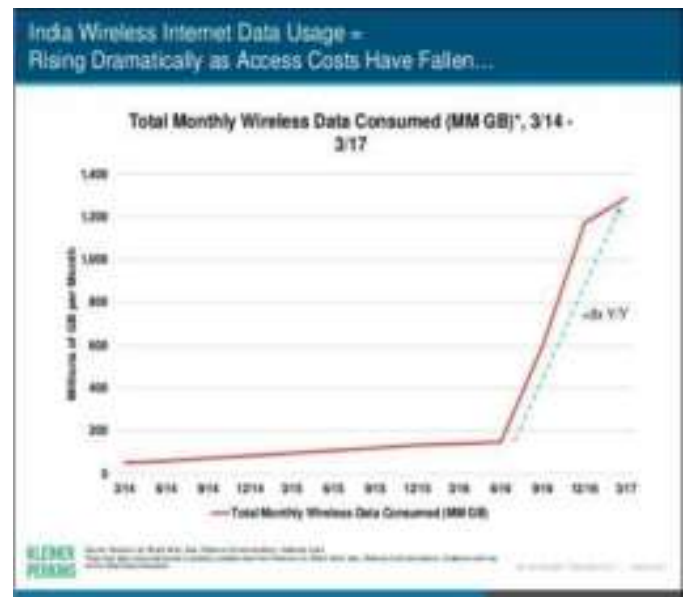

Figure 2:The Effect on the Telecom Industry and Consumers after the Introduction Narsee Monjee Institute of Management Studies [2]

This picture exhibits that each one of the buyers has Jio as heartfeltly grasped and attracted to its contributions and various other of them are so dynamical their activity, Jio's administrators accept that it offers the best assistance at a sensible rate for offices.

As of February 2019, with regards to the telecom regulatory authority of India (TRAI), India has 1.17 billion phone memberships, as a degree improvement in versatile memberships. This infers that since August 2016 (Month of Jio Launch), partner degree expansion of almost 100 forty million memberships.

Advancement is particularly articulated in village/rural regions, there are right now around 500,000,000 occupants. Close to 80 million extra broadband memberships than there have been before the corporate was based. As extra Indians get memberships on the telephone, there are more individuals developing on-line. [3]

Let's see the subscribers number as per operator's as of 22/12/2018 (in Crores):

\begin{tabular}{|l|r|r|r|r|r|r|r|r|r|r|}
\hline Company & $\begin{array}{c}2008 \\
-09\end{array}$ & $\begin{array}{c}2009 \\
-10\end{array}$ & $\begin{array}{c}2010 \\
-11\end{array}$ & $\begin{array}{c}2011 \\
-12\end{array}$ & $\begin{array}{c}2012 \\
-13\end{array}$ & $\begin{array}{c}2013 \\
-14\end{array}$ & $\begin{array}{c}2014 \\
-15\end{array}$ & $\begin{array}{c}2015 \\
-16\end{array}$ & $\begin{array}{c}2016 \\
-17\end{array}$ & $\begin{array}{r}2017 \\
-18\end{array}$ \\
\hline $\begin{array}{l}\text { Relinner } \\
\text { Jio }\end{array}$ & & & & & & & & & 11 & 19 \\
\hline $\begin{array}{l}\text { Bhanti } \\
\text { Airtel }\end{array}$ & 10 & 13 & 17 & 18 & 19 & 21 & 23 & 25 & 28 & 31 \\
\hline Vodafone & 7 & 10 & 13 & 15 & 15 & 17 & 18 & 20 & 21 & 22 \\
\hline B5NL & 8 & 10 & 12 & 12 & 12 & 11 & 9 & 10 & 12 & 12 \\
\hline Idea & 4 & 6 & 9 & 11 & 12 & 14 & 16 & 18 & 19 & 20 \\
\hline Total & 29 & 39 & 51 & 57 & 59 & 62 & 66 & 73 & 90 & 104 \\
\hline
\end{tabular}

ble 2: DoT compiled data from Telecom Statistics India Report 2018 accessed on 22/12/2018 [5] 


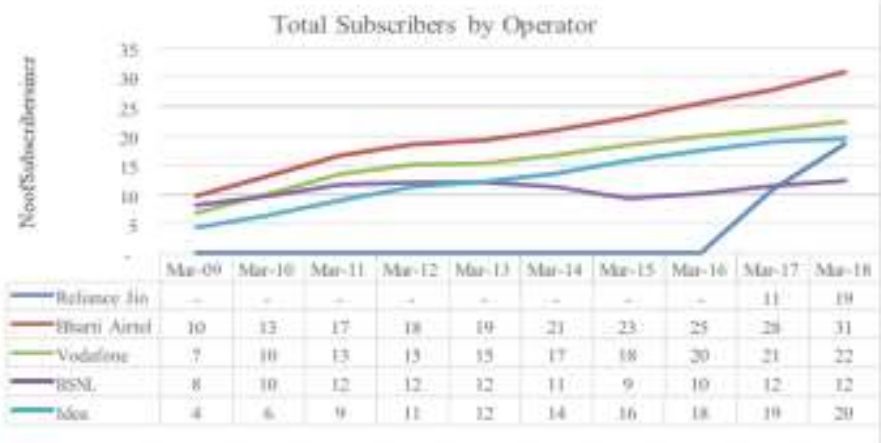

Figure 3: A Study Report On Reliance Jio Infocomm Limited IISc [3]

\subsection{Reliance Jio's direct benefits with TRAI}

Reliance Jio became a sensation in the Republic of India within an awfully temporary amount of your time. The shares of Reliance, having languished for many years, took off in early 2017 once it proclaimed that Jio can emerge from its trial section and begin charging for service. Since then, the shares have nearly doubled. A price-cutting war has arisen between telecommunication suppliers and people are able to access facilities at terribly low prices.

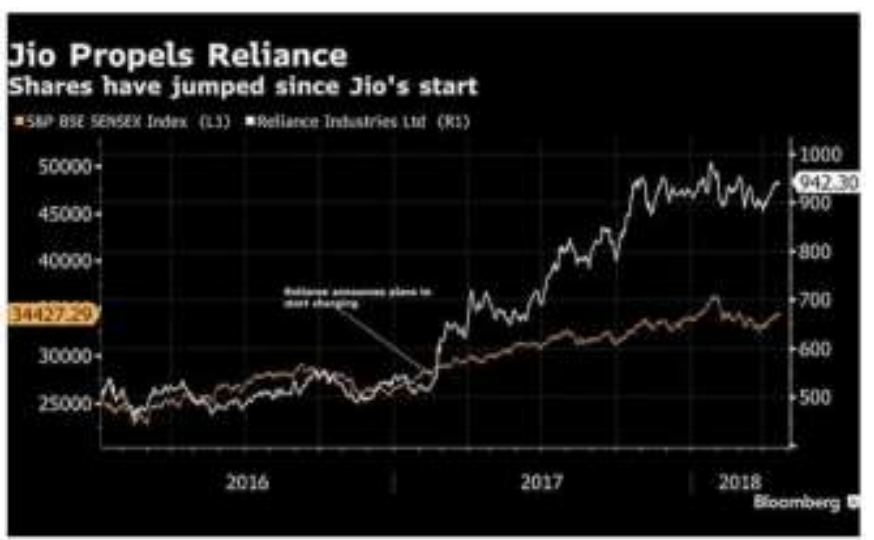

Figure 4: Rise in Profits for Reliance after JIO's introduction [4]

For the telecommunication business, the principles and laws are framed by TRAI. The rising of Jio prompted the rival to threaten the systems and deals of Jio. In TRAI, their interests are invoked by rivals. The remainder of the telecommunication business powerfully criticized TRAI for permitting RIL to check its network property for 253 days.

The controller moreover caused a commotion quickly when Jio turned into the main data provider in the Republic of India to dispose of data share from its depiction of what comprises' significant market power. Savage valuation is once, to get an ideal situation over elective administrator in that circle, An administrator with more than thirty p.c piece of the overall industry in that circle drops rates.
TRAI laws express that it might prompt a punishment of up to Rs fifty lakhs for every circle wherever seen as blameworthy of predatory pricing. This prevents Jio from cutting rates more. Jio has interminably attempted to join its development with the Digital-India activity of the govt. The public authority's partiality has never-endingly been inside the press. TRAI has also required fines on the corporate for missing out on several quality benchmarks.

\section{CONCLUSION}

Because of feeble government approaches and in this manner the absence of modernization of foundation, BSNL has unquestionably endured in the course of the most recent 20 years. Before the finish of 2019, it totally was accumulated in obligations with industrious advance requests exclusively to pay the wages of its staff that are incomplete for quite a long time. With the corporate barely living when being coated in huge quantities of debt, it's troublesome to inform however things are attending to prove within the end of the day. because it was one among the previous couple of public sectors, they got numerous public support. Before the trade was absolutely controlled by firms, it absolutely was necessary for it to carry the market. BSNL devices and towers that folded as a result of they weren't maintained had created their customers impatient. Since BSNL couldn't answer these queries, in search of a safer link, it created a lot of customers depart. .[1]

Returning to Jio, it turned into India's biggest medium administrator essentially just one year once it's revealing towards the finish of 2019. The organization was furthermore India's first provider of telecoms to cross 400,000,000 clients. In accordance with the latest reports released by TRAI, Jio these days has a very $52 \%$ piece of the pie inside the Indian landmass. [6]

\section{ACKNOWLEDGMENT}

I thank Dr. Komal Singla, (Department of Mathematics, Chandigarh University) for her guidance and useful discussion.

\section{REFERENCES}

[1] Arshad Ahamad "Infant company beats Industry Titan: How Jio Buried BSNL" (2020)

[2] Niharika Rajan, Neetu N, Anjumol K S, Sreelakshmi Sandeep "A Study Report On Reliance Jio Infocomm Limited" (2019) : 35

[3] Prof Vishal Gupta , Prof Rekha Jain, Prof Ajay Pandey "Report on Revival /Restructuring of BSNL" (2018): 4-22

[4] Bhuma Shrivastava and Saket Sundria: Bloomberg "Mukesh Ambani's New Telecom Unit Poised to Report Profit" (2018)

[5] "Telecom Statistics India Report" data compiled by DoT (2018)

[6] "Economics Research. Unit Department of Telecommunications Ministry of Communications Government of India New Delhi" Telecom Statistics India (2019) 